Review

\title{
Cortactin in cancer cell migration and invasion
}

\author{
Miao Yin ${ }^{1, *}$, Wenqing Ma ${ }^{1, *}$ and Liguo An $^{1}$ \\ ${ }^{1}$ Shandong Provincial Key Laboratory of Animal Resistance Biology, College of Life Sciences, Shandong Normal University, \\ Jinan 250014, China \\ *These authors contributed equally to this work
}

Correspondence to: Miao Yin, email: yinmiao@sdnu.edu.cn

Keywords: cortactin, Arp2/3 complex, cancer cell, cell migration, cell invasion

Received: November 30, $2016 \quad$ Accepted: August 29, $2017 \quad$ Published: September 19, 2017

Copyright: Yin et al. This is an open-access article distributed under the terms of the Creative Commons Attribution License 3.0 (CC BY

3.0), which permits unrestricted use, distribution, and reproduction in any medium, provided the original author and source are credited.

\section{ABSTRACT}

\begin{abstract}
Cortactin, a substrate of sarcoma (Src) kinases, is an actin-binding protein that is involved in cytoskeletal regulation, and is frequently overexpressed in cancer cells. Binding to the actin related protein 2/3 (Arp2/3) complex stimulates cortactin activity, which promotes F-actin nucleation and assembly. Cortactin promotes cancer cell migration and invasion, and plays a pivotal role in invadopodia formation and extra cellular matrix degradation. Overexpression of cortactin, by amplification of the chromosomal band 11q13, increases tumor aggressiveness. In this review, we report on the current knowledge and potential mechanisms of action of cortactin as a critical mediator of cancer cell migration and invasion.
\end{abstract}

\section{INTRODUCTION}

Cortactin, a prominent actin-binding protein, was initially character as a component of the Src non-receptor tyrosine kinase $\mathrm{pp} 60^{\mathrm{src}}$. The name cortactin derives from the localization "cortical actin" structures [1,2]. Cortactin acts as an actin assembly protein and plays a role in the assembly of branched actin and maintaining its stability via bind an Arp $2 / 3$ complex [3, 4]. Indeed, cortactin has been found at sites of dynamic actin assembly incellular protrusions, such as in lamellipodia and invadopodia $[5,6]$. Cortactin can be phosphorylated by tyrosine and serine/threonine kinases [7], making cortactin an important regulatory target. Moreover, cortactin is critical for membrane trafficking and promotes the secretion of extracellular matrix (ECM)-degrading proteinases, which are crucial for the invadopodia formation and its function in tumor cell metastasis. Cortactin has been thus recognized for its association with cell motility and invasion $[8,9]$.

Cortactin has been demonstrated to be associated with cancer. For example, gene amplification studies have shown that the gene EMS1 (from human) encodes cortactin, which was overexpressed in a variety of tumors, such as breast cancers as well as head and neck tumors [10]. In addition, overexpression of cortactin enhances cell migration, invasion, and tumor cell metastasis [11].
Here, we provide an overview of the roles of cortactin, emphasizing the interaction with the actin cytoskeleton as well as the roles of cancer cell migration and invasion.

\section{CORTACTIN INTERACTS WITH ACTIN CYTOSKELETON}

\section{Cortactin structure}

Cortactin, a $63-65 \mathrm{kDa}$ protein, was firstly identified as a phosphorylated substrate of v-Src-transformed chick embryo fibroblasts $[12,13]$. The prediction of cortactin structure based on amino acid sequence shows that cortactin consists of four major domains: N-terminal acidic (NTA), 6.5 tandems repeat, proline-rich domain, and the C-terminal Src homology 3 domains (SH3 domains) $[14,15]$ (Figure 1). The NTA domain play a role in binding and activating the Arp $2 / 3$, and the process is involved in dynamic assembly of branched actin networks [16]. The NTA domain is localized between amino acid residues 15 and 35, and contains a conserved aspartic acidaspartic acid-tryptophan (DDW) motif at residues 20-22, which is required for binding the Arp3, a subunit of Arp2/3 [17]. The DDW motif has highly conserved sequence, and its function is equivalent to the verprolin-cofilin-acidic (VCA) domain which is the Wiskott-Aldrich syndrome 
protein (WASP) family proteins [16, 17]. The NTA region is followed by a series of six complete 37 amino acid tandemly repeating segments, and one incomplete segment 20 residues in length [18]. These repeats, named 'cortactin repeats' [19], form a helix-turn-helix motif [12]. The cortactin repeats mediate cortactin binding to F-actin along with its co-localization with the cortical actin network $[15,16]$. The fourth repeat is required to binding F-actin, whereas the third and fifth repeat are essential for maintaining the binding efficiently [20]. Derived from reversible polymerization of G-actin, F-actin supply the structural framework and mechanical forces that regulate morphological changes within the cell [20]. The process is also promoted by the Arp $2 / 3$ complex, which makes F-actin branching start $[21,22]$. Following the 6.5 tandems repeat region, a proline-rich domain [23] is an $\alpha$-helical domain of variable length (48-52 amino acid residues) that is enriched in sites of tyrosine, serine, threonine phosphorylation residues [12]. And a SH3 domain at the distal C-terminus mediates the interaction with proteins involved in diverse cellular functions. An abbreviated list of proteins that interact with cortactin is presented in Table 1. A great many of cytoskeletal proteins involved in the process of membrane trafficking, which bind to the cortactin SH3 domain, indicated that the cortactin acts as scaffold in the arrangement of cytoskeleton and the membrane trafficking [24].

\section{SH3 domain-binding partners}

The principal function of cortactin is activating the actin cytoskeleton assembly via promoting and stabilizing the branched chained F-actin networks is induced by Arp2/3 complex [17]. The underlying mechanisms involved in this process have been described in several reviews $[25,26]$. In addition, cortactin interacts with multiple binding partners at the site of actin polymerization.

The identification of cortactin SH3 domain-binding partners has provided novel insight into how cortactin promotes distinct cellular processes [27]. These proteins include Neural WASP (N-WASP), WASP-interacting protein (WIP), and dynamin 2 [28]. Among them N-WASP activates the Arp2/3 complex strongly $[17,29]$. In spite of the fact that cortactin and N-WASP are able to binding the Arp2/3 and initiating the polymerization of actin $[16,17,30]$, cortactin is weaker than N-WASP in stimulating the Arp2/3 [4, 16, 31]. Recent studies have shown that localization of cortactin was similar with $\mathrm{N}$-WASP, as they are all localized at the site of actin assembly [17, 32]. Consequently, a pattern has been proposed where the Arp2/3 interacts with N-WASP and cortactin in sequence [17]. Although the main function of cortactin involves stabilizing of filament branches, N-WASP alone or in combination with cortactin stimulates the Arp2/3, bring forth the branched chained polymerization of F-actin [17, 30]. WIP also binds to the SH3 domain and promotes the capable of cortactin activate to Arp2/3 [13, 33]. Similarly, the cortactin-binding domain affects the localization of WIP at the cell cortex area $[13,34]$. The association between cortactin-WIP complex and actin filaments, are essential for the maximal achievement of Arp2/3 activity, indicating a new finding that cortactin can link WIP to pre-existing filaments $[13,35]$. WIP is also involved in the process of reducing the depolymerization of actin filaments and stabilizing the actin branch points $[13,36]$. Dynamin 2 interacts with cortactin and this interaction, which is necessary for

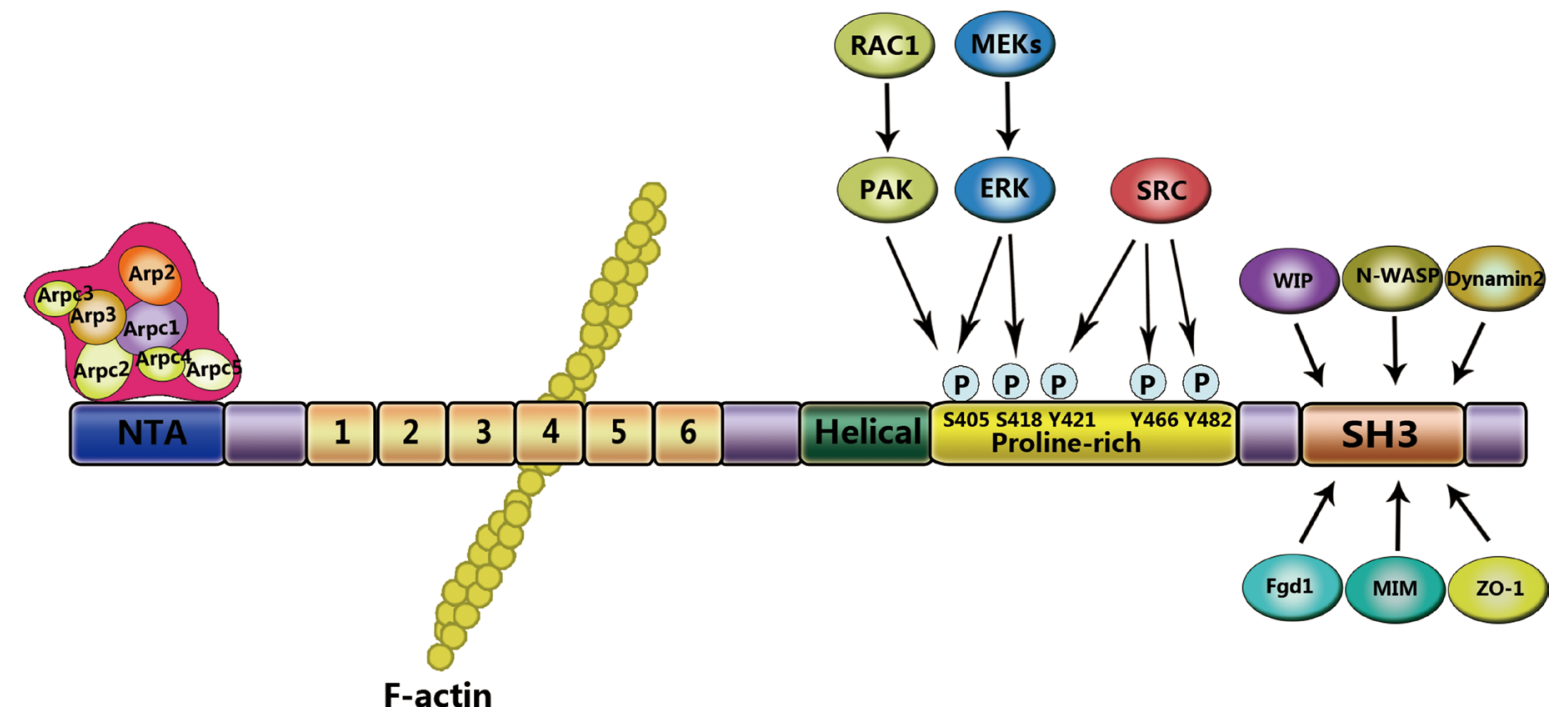

Figure 1: Structural domains of cortactin. Cortactin consists of distinct domains that interact with different signaling molecules. The NTA domain is located at the N-terminus and interacts with and directly activates the Arp 3 subunit of the Arp $2 / 3$ complex. The fourth repeat of the cortactin repeats region binds to F-actin. At the C-terminus, the proline-rich domain contains phosphorylation sites for serine/ tyrosine kinases. The SH3 domain mediates binding to cytoskeletal, membrane trafficking, and signaling proteins. 
Table 1: Cortactin-binding partners

\section{(A) Binding partners of cortactin associated with actin assembly}

\begin{tabular}{lll}
\hline Cortactin binding proteins & Cortactin binding site & Function \\
\hline Arp2/3 & NTA & Actin nucleation \\
Actin filaments & Repeat regions & Cytoskeletal polymer \\
Caldesmon & N-terminus & Actin binding protein \\
N-WASP & SH3 & Actin assembly \\
WIP & SH3 & Adaptor protein, Actin binding/assembly, WASP stabilization \\
MIM & SH3 & Adaptor protein, Actin binding and regulation \\
\hline
\end{tabular}

(B) Binding partners of cortactin associated with phosphorylation and acetylation

\begin{tabular}{lll}
\hline Cortactin binding proteins & Cortactin binding site & Function \\
\hline HDAC6 & Repeat region & Deacetylase \\
SIRT1 & Repeat regions & Deacetylase \\
Met & Unknown & Receptor tyrosine kinase \\
Syk & Unknown & Tyrosine kinase \\
PTP1B & Tyr446 & Tyrosine phosphatase \\
Nck1 & Phospho-Y421, 466 & Signaling adaptor \\
Src family kinases (Src, Fer) & phospho-Y421, 466, 482 & Tyrosine kinase \\
ERK1/2 & S405, 418 & Serine/threonine kinase \\
PAK1 & S113 & Serine/threonine kinase \\
Abl/Arg & SH3 & Tyrosine kinase \\
\hline
\end{tabular}

\section{(C) Binding partners of cortactin associated with membrane trafficking}

\begin{tabular}{lll}
\hline \multicolumn{1}{c}{ Cortactin binding proteins } & Cortactin binding site & \multicolumn{1}{c}{ Function } \\
\hline p120 catenin & N-terminus & Cell-cell adhesion via cadherin stability \&trafficking \\
Hip1R & SH3 & Membrane trafficking \\
ASAP1/AMAP1 & $\mathrm{SH} 3$ & Membrane trafficking, Signal transduction \\
Dynamin2 & $\mathrm{SH} 3$ & GTPase, Membrane trafficking \\
BK channels & $\mathrm{SH} 3$ & Membrane excitability \\
K+ channel Kv1.2 & Unknown & Membrane excitability \\
\hline
\end{tabular}

\section{(D) Binding partners of cortactin associated with signal transmission}

\begin{tabular}{lll}
\hline Cortactin binding proteins & Cortactin binding site & Function \\
\hline Grb2 & N-terminus & Signaling adaptor \\
BPGAP1 & SH3 & RhoA-GAP \\
CortBP1/SHANK2 & SH3 & Synaptic plasticity, adaptor protein, regulates Na+/H+ exchanger 3 \\
FGD1 & SH3 & Cdc42-GEF \\
ASAP1/AMAP1 & SH3 & Membrane trafficking, Signal transduction \\
\hline
\end{tabular}


actin polymerization, and the $\mathrm{SH} 3$ domain and two motifs within the dynamin proline-rich domain serve as mediator in this process $[17,37]$.

\section{Cortactin activates the Arp2/3 complex and regulates the assembly of branched actin}

The Arp2/3 complex is the main molecular regulator of actin polymerization, which is necessary for acting nucleation and forming a branched actin filament networks within cells $[38,39]$. The branched actin networks provide to the structural of plasma membrane and processes, for example the formation of lamellipodia [40], pathogen motility, vesicle trafficking, and formation of cell-cell junctions [41, 42].

In vitro, half of the $\mathrm{N}$-terminal portion of cortactin (amino acid residues 1-326) can be used to bind F-actin and induct the actin filament assembly via stimulating the Arp2/3 [16, 43]. Cortactin directly binds to Arp2/3, and thereby causes a conformational alteration [44]. Given that the binding site of cortactin partially overlaps with WASP [45], WASP-cortactin-Arp $2 / 3$ complex may be inform of a ternary complex [46]. Otherwise, cortactin can take the place of WASP to combine the Arp2/3 complex [30], and then stabilize branches and liberate WASP for a next new cycle [46]. An alternative mechanism includes cortactin binding to WASP by the SH3 domain [28]. The SH3 domain may enhance actin nucleation via binding to the WASP, WIP, and dynamin 2 [46]. Once the Arp $2 / 3$ is activated, it will bind to a pre-existing actin filament and then produce a new filament, which with a $70^{\circ}$ branch [47]. When the structure is formed, cortactin stabilizes branched actin networks. Inhibition to debranching appears to be a unparallel and essential function of cortactin [48].

Several studies have shown that activation of N-WASP is induced by cortactin involved in binding to its proline-rich domain and decreasing auto-inhibition $[19,49]$. Furthermore, the SH3 domain contains many adaptor proteins, for instance, Nck and growth factor receptor-bound protein 2 (GRB2) [50]. These adaptor proteins have ability to stimulate N-WASP by binding to the proline-rich domain $[51,52]$. In a word, the SH3 domain has capability to stimulat the Arp2/3-mediated actin polymerization by means of activating N-WASP, and thereby promotes cell migration [53]. In addition, Srcmediated tyrosine phosphorylation of cortactin regulates cell movement (Figure 2).

\section{CORTACTIN PROMOTES CELL MIGRATION}

\section{The role of cortactin in podosome and invadopodia formation}

Cell migration through interstitial tissues is related to specialized characteristics of the migrating cell, in particular the development of proteolytic membranous invadopodia and podosome [54]. Invadopodia are actin-based membrane protrusions which are localized on the basal surface of invading cells, and these cells involved in a serious of cellular processes, for instance the assembly of branched actin, adhesion, cell signaling and proteases secretion that spatially converge to promote ECM remodeling $[53,55,56]$. Podosomes are similar to invadopodia, whereas the former was found in normal cells which play a role in crossing tissue barriers or ECM remodeling [57].

Cortactin are capable of stimulating the endurance of invadopodia [58], except, inducing formation of the protrusions [58-62]. Cortactin also improve the capability of the cells to produce dominant invadopodia in response to stimulation of growth factor [61]. Furthermore, cortactin facilitates the novel adhesions formation at the edge of cells, which may contribute to invadopodia persistence and migration [58]. Defects in invadopodia endurance, adhesion molecule, and cellular move ability can be fully supplemented via the modify function of the cortactin derivatives which only include the Arp2/3 and F-actin binding domain $[63,64]$. This suggests that cortactin is responsible for direct stimulation of the assembly and/or stability of branched actin mediated by Arp2/3 [32, 58]. The cortactin phosphorylation via Src kinase is required for podosome formation mediated by cortactin $[17,65]$. Webb et al. demonstrated that cortactin is crucial for the formation of podosome, an intact SH3 domain which is necessary for cortactins transposition to early podosomes $[17,66]$. The SH3 domain stimulates N-WASP, thereby suggesting that cortactin are likely to furnish a scaffold for the polymerization of actin $[17,67]$. On the flip side, the actin-binding repeated domain of cortactin was founded playing a role in the advanced stages of podosome formation $[17,66]$. As above mentioned, the dynamin is necessary for the formation of podosome in normal cells $[17,68,69]$. The interaction between cortactin and WIP may be involved in the formation of podosome, suggesting that when both the proteins consist in the podosomes, the co-expression of them will promotes the membrane protrusions [17, 35].

\section{Post-translational modifications of cortactin in cell migration}

\section{Tyrosine phosphorylation of cortactin}

Cortactin interacts with numerous binding partners [24], and is activated by several post-translational modifications. Cortactin was initially characterized via its tyrosine phosphorylation activity, in v-Src transformed cells $[1,47]$. Src kinase phosphorylates cortactin at three tyrosine residues, include Y421, Y466, and Y482 [17, 47]. Tyrosine phosphorylation occurs primarily at Y421 and Y466, the two sites are localized within the proline-rich domain $[70,71]$. However, mapping of post-translational modifications by mass spectrometry has resulted in the 
identification of additional targets, including Y482 [72]. Interestingly, tyrosine phosphorylation of cortactin occurs with a progressive manner, with the phosphorylation initially occurring at the site of Y421 and whereafter, at the site of Y466 [17, 73]. The phosphorylation of Y421 via Src creates a binding site for the cortactin SH2 domain [74-76] that is whereafter phosphorylation of Y466, or other sites. Several non-receptor tyrosine kinases have been involved in the phosphorylation of cortactin [77], including members of Src kinase family, ABL kinase family, FER, and Syk [78-80]. It has been demonstrated that in cancer cells, activation of hepatocyte growth factor receptor (HGFR, also known as MET), human epidermal growth factor receptor 2 (HER2, also known as ERBB2), and tyrosine kinases stimulates cortactin phosphorylation [81].

At the mechanistic level, tyrosine phosphorylation triggers the recruitment of SH2-domain proteins, including kinases, and the cytoplasmic protein Nck adaptor protein 1 (Nck1), which links cortactin with N-WASP and WIP, enhancing the activation of the Arp2/3 complex [3, 4, 82]. These findings are consistent with the observation that tyrosine phosphorylation of cortactin induces lamellipodia protrusion and cell migration [83]. The phosphorylation of tyrosine involved in cortactin functionality is a intricate phenomenon, unmasked a mass of processus biologique involving cortactin [17]. So the level of cortactin phosphorylation is positively related to its capability to lead to cell migration $[17,84]$.

\section{Serine/threonine phosphorylation of cortactin}

In addition to tyrosine phosphorylation, cortactin can be phosphorylated by serine/threonine kinases, including extracellular signal-regulated kinase (ERK)/ MAP kinases, protein kinase D (PKD), and p21-activated kinase (PAK) [85]. Indeed, ERKs, also known as MAPKs can phosphorylate cortactin at residues S405 and S418 [19]. The serine phosphorylation mediated via ERK may promote the process of the $\mathrm{SH} 3$ domain interacts with sequences within the proline-rich domain. The interaction impels cortactin to bind N-WASP, increasing the polymerization of actin mediated via the Arp2/3 [7]. PKD phosphorylates cortactin at S298, which increases cell migration due to the activation of the Arp $2 / 3$ $[5,86]$. Besides the S298, PKD also phosphorylates S348 in invadopodia of breast cancer cells [87]. Reaction to the growth factor receptor stimulation [88], the serine/ threonine-protein kinase PAK3 phosphorylates cortactin at S113 [85]. PAK1 phosphorylates cortactin at S405 and S418, downstream of RAC1 and CDC42 [77]. Both the RAC1 and CDC42 are components of the small GTPases Rho family that are required for localizing cortactin at the cellular edge, increase the association of cortactin with N-WASP $[89,90]$.

\section{Acetylation of cortactin}

In addition to phosphorylation, cortactin activity can also be modulated by acetylation by histone

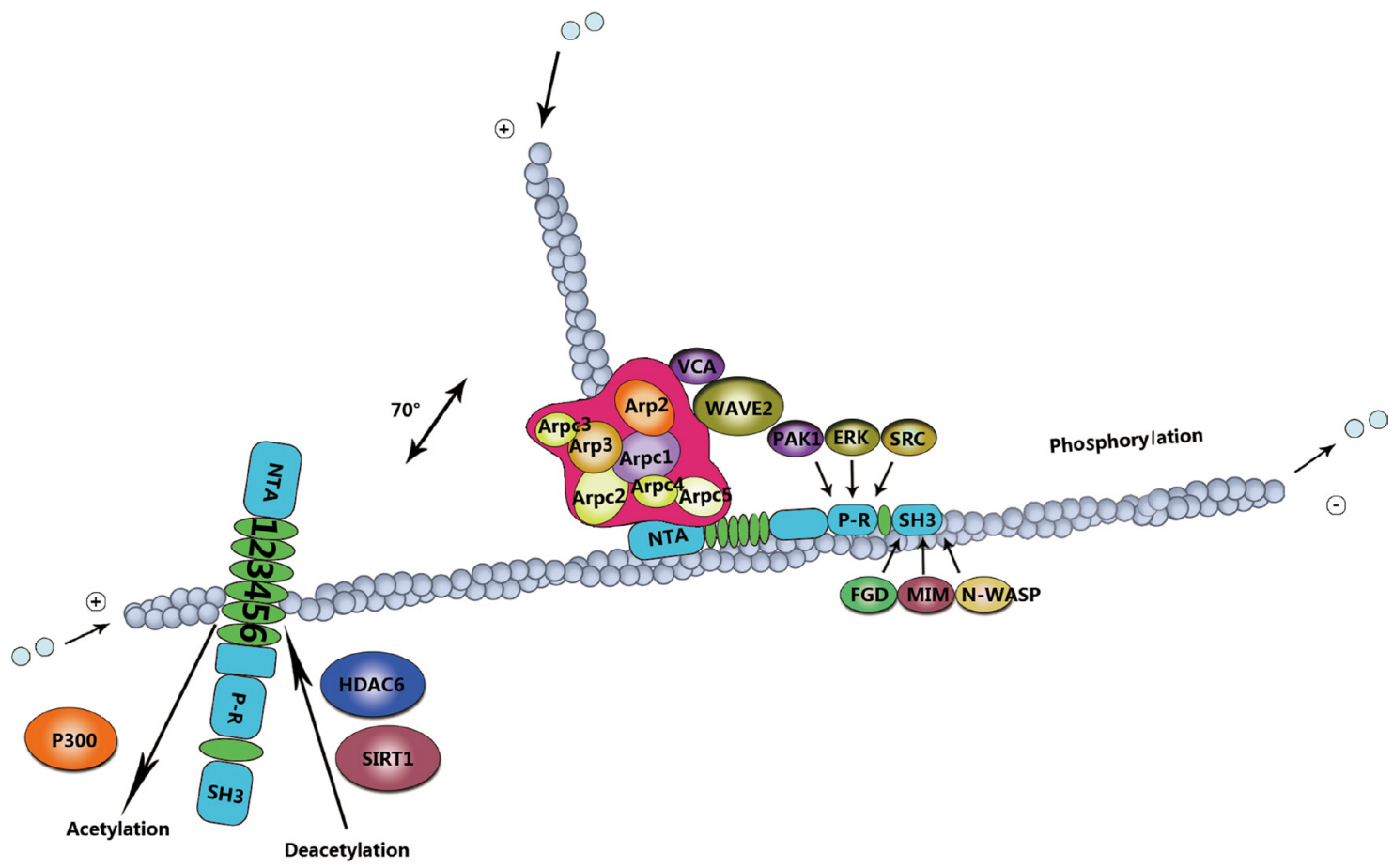

Figure 2: Mechanism of cortactin post-translation modifications in cell migration. The role of cortactin in actin assembly depends on phosphorylation and acetylation events. Erk phosphorylation regulates the intramolecular interaction or induces conformational changes in cortactin, leading to binding to the N-WASP-Arp $2 / 3$ complex for actin polymerization. Src activation can directly nullify the Erk effect, ensuring actin disassembly. This intricate balance in actin organization is important for cell migration, acetylation by p300, and deacetylation by HDAC6 and SIRT1. 
acetyltransferase p300, and deacetylation by histone deacetylase 6(HDAC6) and sirtuin-1 (SIRT1) [91, 92]. Acetylation neutralizes charged lysine (Lys) residues within the binding domain of F-actin [93, 94], thereby abrogating the capability of cortactin to bind F-actin and decreasing cells motility $[94,95]$. Recently, HDAC6 has been acting on enhance the binding capacity of cortactin to actin filaments via modifying a charge patch in the repeats domain $[95,96]$. Similar as in many cortactin regulatory mechanisms, acetylation appears to play an essential role in the cancer progression [97]. For example, HDAC6 expression is necessary for the the formation of invadopodia and degradation of ECM in breast cancer cells [97-100].

\section{THE ROLE OF CORTACTIN IN TUMOR INVASION}

\section{Cortactin function in membrane trafficking and secretion of matrix metalloproteinases}

Tumor cell metastasis progress depends on the activation of invadopodia for the degradation of ECM barriers [101]. Cortactin promotes membrane trafficking and recruits ECM-degrading proteinases to invadopodia sites, thereby cortactin made an essential role in the process of degradation of ECM associated with invadopodia [102]. Membrane trafficking plays a role in the formation of invadopodia, for this function is mainly dependent on the secretion of protease in the process of ECM degradation [103, 104]. One possible way to explain this mechanism is promote cell migration and invasion via the affection of cortactin on the proteins, including actin polymerization and/or bridging membrane trafficking to the actin cytoskeleton to increase membrane trafficking. In this process cortactin represents an indirect link between special transmembrane receptors and the actin cytoskeleton. This usually happens through the interaction of the SH3 domains with sub-membranous scaffolding proteins.

Cortactin and its several binding proteins are involved in the process of protein trafficking (Table 1). It has been reported that cortactin recruitment preceded the proteases trafficking to the sites of ECM degradation [105]. In addition, the cortactin and phosphotyrosine signaling may be essential to delivery and/or activate the proteases which associated with invadopodia [106]. In addition, cortactin has been shown to be crucial for trafficking the key invadopodia proteases, including matrix metalloproteinase 1 (MMP1), MMP2, and MMP9 from late endosomes to the plasma membrane, which play a crucial role in the invasive potential of cancer cells (Figure 3) [53, 107, 108]. Recent research conducted by Zhao et al. showed that a synergistic reaction was exhibited on cortactin and Exo70, which could simultaneously stimulate the secretion of MMPs and thus regulate tumor invasion [109]. Exo70 a key subunit of the exocyst complex, was involved in regulating the cell migration and invasion through interaction with microfilaments [38].

\section{Cortactin is crucial for tumor invasion}

Cortactin have essential role in human neoplasia [8]. A large number of evidences indicate that cortactin is overexpressed in various types of human cancers [47], such as head, neck, and esophageal squamous carcinomas, colorectal carcinoma, gastric cancer, hepatocellular cancer, breast cancer, and ovarian cancers [9, 110-113]. Cortactin overexpression is frequently due to chromosomal amplification of the 11q13 region [111] that is localized in the cortactin-encoding EMS1 gene [114]. This gene has a large region containing several known or potential oncogenes [53]. This amplicon included several genes found in human tumors frequently, such as oncogenes Cyclin D1 (encoded by CCND1/PRAD1), INT2/Fibroblast growth factor 3 (FGF3), human serum thymus factor/FGF4 and BCL1 [24]. CCND1, a gene located in the chromosomal region. There are four 'cores' of gene amplification within the $11 \mathrm{q} 13$ regions, among which CCND1 and EMS1 have been identified as the prime candidate genes to promote their respective cores amplification [53]. Unlike many other genes, these cores are usually overexpressed upon amplification [24]. Cortactin has been associated with poor prognosis estrogen receptor-negative breast cancer, whereas cyclin D1 has been associated with the positive [115]. The fact that the cortactin can still be amplified without cyclin D1 amplification [115], suggests that EMS1 amplification directly involved in tumor progression. Cell lines isolated from patients with 11q13 amplification exhibited increased levels of cortactin mRNA and protein, providing strong circumstantial evidence that cortactin overexpression plays an important role in tumors with 11q13 amplification. In addition, cortactin overexpression inhibited the degradation of epidermal growth factor receptor, leading to increased pro-mitotic receptor signaling [116, 117].

Recent studies have supported the cortactin role in metastasis, which is consistent with its function in cell motility and ECM degradation [118-120]. Indeed, cortactin expression is a key factor in ECM secretion, which dictates cell migration and may explain diverging theories regarding the importance of cortactin in cell motility [102]. For example, studies have shown that the loss of cortactin does not affect cell migration when cells grow on an ECM [121]. However, in the absence of an ECM, cells in vitro showed a pronounced defect in cell migration, suggesting that cortactin is crucial for cell migration in absence of an ECM [102].

\section{PERSPECTIVES}

We reviewed the state of the art of researches that a Src kinase substrate, cortactin plays an essential role in 
regulating a myriad of cellular processes, such as actin polymerization, podosome/invadopodia formation, and tumor metastasis [88]. These cellular processes may be relevant to the etiopathogenesis of human cancer [17]. We reviewed the work done to identify the actin nucleationpromoting factor cortactin as a essential regulator of actin cytoskeletal dynamics. Cortactin a enables coupling of two key biological characteristics, and it can also regulating the nucleation and stabilization of branched actin networks mediated via Arp2/3 [29], for another its SH3 domain-mediated targeting to specific protein complexes. However, more insight is required to clear whether the multiple mechanisms are operative in different cellular functions, such as the cortactin as a scaffolding protein, stimulates the Arp2/3 directly or not, and the role in stabilization of branches [122]. We reviewed reports that the post-translational modifications of cortactin are essential in the process of cell motility and morphological changes. However, the results of phosphorylation remain controversial. For example, in invadopodia, the disruption of tyrosine phosphorylation sites of cortactin prevented cell edge protrusion, cancer cell invasion, and actin polymerization $[82,123]$. However, other studies have shown that, disrupted phosphorylation promoted interactions between cortactin and N-WASP, and enhanced the stimulation of Arp2/3 [7].

We also reviewed the literature that the role of cortactin in tumor invasion. Cortactin affects cell aggressiveness via regulating MMP secretion and ECM degradation [102]. Known as an important regulator in ECM degradation, cortactin which is associated with invadopodia promotes membrane trafficking and recruits ECM-degrading proteinases to invadopodia sites. Recently, a report showed that a synergistic reaction exhibited on cortactin and Exo70, which could mediate the secretion of MMPs, and thus regulate tumor invasion [109]. However, the interaction mechanism between cortactin and Exo70 is unclear. Finally, we reviewed reports that cortactin is overexpressed in many cancers through 11q13 amplification. However, further studies are required to make clear the mechanization of the chromosome 11q13 amplification and cortactin overexpression in cancer cells.

In summary, cortactin is crucial for many cancer cellular processes. However, more insight is required to clarify the functions of cortactin in tumor progress and the

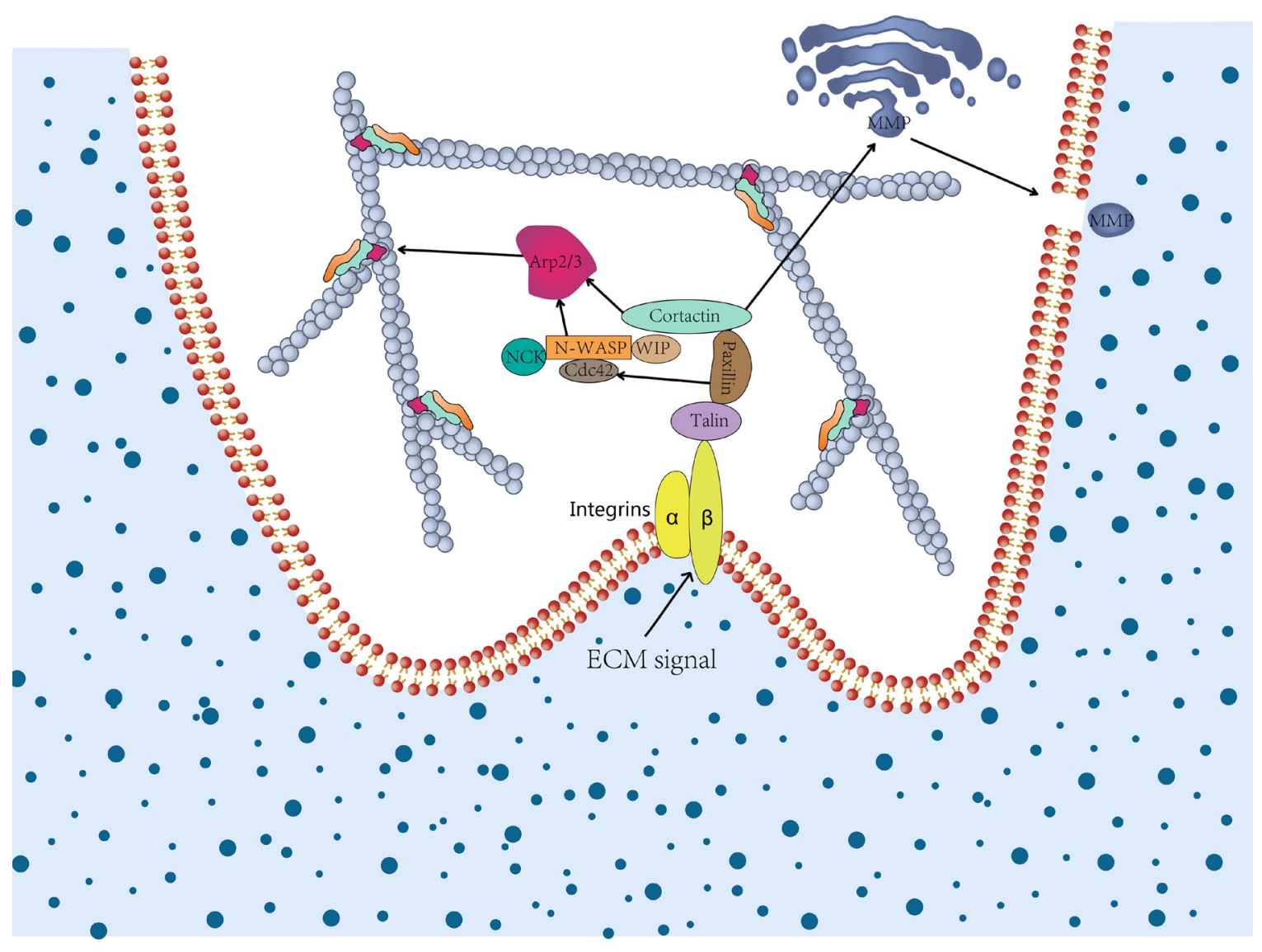

Figure 3: The role of cortactin in invadopodia formation and extracellular matrix degradation. In cancer cell invasion, cortactin contributes to invadopodia formation and extracellular matrix (ECM) degradation. The former relies on the activation of N-WASP via Nck, Cdc42 via paxillin, and coactivation of the Arp2/3 complex. The latter relies on secretion of MMPs and vesicular trafficking to invadopodia via regulation of post-Golgi trafficking or vesicle capture. Once ECM degradation is established, invadopodia may live longer due to positive feedback. 
tumor microenvironment, the binding domains of cortactin in promoting the aggressiveness of cancer cells. An intensive study of the cortactin role in tumor may lead to identifying some new therapeutic strategies to treat cancer.

\section{Abbreviations}

Arp2/3 complex: actin related protein 2/3 complex; ECM: extracellular matrix; NTA: N-terminal acidic; SH3: Src homology; VCA: verprolin-cofilin-acidic; N-WASP: Wiskott-Aldrich syndrome protein; WIP: WASP-interacting protein; HGFR: hepatocyte growth factor receptor; HER2: human epidermal growth factor receptor 2; ERK: extracellular signal-regulated kinase; PKD: Protein kinase D; PAK: p21-activated kinase; HDAC6: deacetylase 6; SIRT1: sirtuin-1; MMP: matrix metalloproteinase; CCND1/PRAD1: cyclin D1; FGF3: fibroblast growth factor 3 .

\section{CONFLICTS OF INTEREST}

The authors have no conflicts of interest related to this study.

\section{FUNDING}

This work was supported by grants from Shan Dong Science Foundation for Youths and Shan Dong Science and technology Foundation for College, grant No. BS2011SW049 and No. J13LE05.

\section{REFERENCES}

1. Wu H, Reynolds AB, Kanner SB, Vines RR, Parsons JT. Identification and Characterization of a Novel CytoskeletonAssociated pp6Osrc Substrate. Molecular and Cellular Biology. 1991; 11:5113-5124.

2. Wu H, Parsons JT. Cortactin, an 80/85-Kilodalton pp60 src Substrate, Is a Filamentous Actin-binding Protein Enriched in the Cell Cortex. The Journalof Cell Biology. 1993; 120:1417-1426.

3. Tehrani S, Tomasevic N, Weed S, Sakowicz R, Cooper JA. Src phosphorylation of cortactin enhances actin assembly. Proc Natl Acad Sci USA. 2007; 104:11933-11938.

4. Welch MD, Mullins RD. Cellular control of actin nucleation. Annual review of cell and developmental biology. 2002; 18:247-288.

5. Yamaguchi H, Condeelis J. Regulation of the actin cytoskeleton in cancer cell migration and invasion. Biochimica et biophysica acta. 2007; 1773:642-652.

6. Weaver AM, Young ME, Lee WL, Cooper JA. Integration of signals to the Arp2/3 complex. Current opinion in cell biology. 2003; 15:23-30.

7. Martinez-Quiles N, Ho HY, Kirschner MW, Ramesh N, Geha RS. Erk/Src phosphorylation of cortactin acts as a switch on-switch off mechanism that controls its ability to activate N-WASP. Mol Cell Biol. 2004; 24:5269-5280.

8. Li A, Zhang L, Zhang X, Jin W, Ren Y. Expression and clinical significance of cortactin protein in ovarian neoplasms. Clin Transl Oncol. 2016; 18:220-227.

9. Ni QF, Yu JW, Qian F, Sun NZ, Xiao JJ, Zhu JW. Cortactin promotes colon cancer progression by regulating ERK pathway. International journal of oncology. 2015; 47: 1034-1042.

10. Chien HT, Cheng SD, Chuang WY, Liao CT, Wang HM, Huang SF. Clinical Implications of FADD Gene Amplification and Protein Overexpression in Taiwanese Oral Cavity Squamous Cell Carcinomas. PLoS One. 2016; 11:e0164870.

11. Chuma M, Sakamoto M, Yasuda J, Fujii G, Nakanishi K, Tsuchiya A, Ohta T, Asaka M, Hirohashi S. Overexpression of cortactin is involved in motility and metastasis of hepatocellular carcinoma. J Hepatol. 2004; 41:629-636.

12. Weed SA, Parsons JT. Cortactin: coupling membrane dynamics to cortical actin assembly. Oncogene. 2001; 20:6418-6434.

13. Ammer AG, Weed SA. Cortactin branches out: Roles in regulating protrusive actin dynamics. Cell Motility and the Cytoskeleton. 2008; 65:687-707.

14. Shvetsov A, Berkane E, Chereau D, Dominguez R, Reisler E. The actin-binding domain of cortactin is dynamic and unstructured and affects lateral and longitudinal contacts in F-actin. Cell Motil Cytoskeleton. 2009; 66:90-98.

15. Scott AW, Parsons JT. Cortactin: coupling membrane dynamics to cortical actin assembly. Oncogene. 2001; 20:6418-6434.

16. Uruno T, Liu J, Zhang P, Fan Y, Egile C, Li R, Mueller SC, Zhan X. Activation of Arp2/3 complex-mediated actin polymerization by cortactin. Nat Cell Biol. 2001; 3: 259-266.

17. Buday L, Downward J. Roles of cortactin in tumor pathogenesis. Biochimica et biophysica acta. 2007; 1775:263-273.

18. Weed SA, Parsons JT. Cortactin: coupling membrane dynamics to cortical actin assembly. Oncogene. 2001; 20:6418-6434.

19. MacGrath SM, Koleske AJ. Cortactin in cell migration and cancer at a glance. J Cell Sci. 2012; 125:1621-1626.

20. Lua BL, Low BC. Cortactin phosphorylation as a switch for actin cytoskeletal network and cell dynamics control. FEBS letters. 2005; 579:577-585.

21. Rouiller I, Xu XP, Amann KJ, Egile C, Nickell S, Nicastro D, Li R, Pollard TD, Volkmann N, Hanein D. The structural basis of actin filament branching by the Arp2/3 complex. J Cell Biol. 2008; 180:887-895.

22. Seese RR, Babayan AH, Katz AM, Cox CD, Lauterborn JC, Lynch G, Gall CM. LTP Induction Translocates Cortactin at Distant Synapses in Wild-Type But Not Fmr1 Knock-Out Mice. Journal of Neuroscience. 2012; 32:7403-7413. 
23. Orth J, McNiven M. Dynamin at the actin-membrane interface. Current opinion in cell biology. 2003; 15:31-39.

24. Weaver AM. Cortactin in tumor invasiveness. Cancer Lett. 2008; 265:157-166.

25. Bershadsky A. Magic touch: how does cell-cell adhesion trigger actin assembly? Trends Cell Biol. 2004; 14: 589-593.

26. Weaver AM, Young ME, Lee WL, Cooper JA. Integration of signals to the Arp2/3 complex. Current Opinion in Cell Biology. 2003; 15:23-30.

27. Bertier L, Boucherie C, Zwaenepoel O, Vanloo B, Van Troys M, Van Audenhove I, Gettemans J. Inhibitory cortactin nanobodies delineate the role of NTA- and domain-specific functions during invadopodium formation and cancer cell invasion. FASEB journal. 2017; 31: 2460-2476.

28. Kowalski JR, Egile C, Gil S, Snapper SB, Li R, Thomas $\mathrm{SM}$. Cortactin regulates cell migration through activation of N-WASP. Journal of cell science. 2005; 118:79-87.

29. Engqvist-Goldstein AE, Drubin DG. Actin assembly and endocytosis: from yeast to mammals. Annual review of cell and developmental biology. 2003; 19:287-332.

30. Uruno T, Liu J, Li Y, Smith N, Zhan X. Sequential interaction of actin-related proteins 2 and 3 (Arp2/3) complex with neural Wiscott-Aldrich syndrome protein (N-WASP) and cortactin during branched actin filament network formation. J Biol Chem. 2003; 278:2608626093.

31. Le Clainche C, Pauly BS, Zhang CX, Engqvist-Goldstein AE, Cunningham K, Drubin DG. A Hip1R-cortactin complex negatively regulates actin assembly associated with endocytosis. The EMBO journal. 2007; 26:1199-1210.

32. Helgeson LA, Prendergast JG, Wagner AR, RodnickSmith M, Nolen BJ. Interactions with Actin Monomers, Actin Filaments, and Arp2/3 Complex Define the Roles of WASP Family Proteins and Cortactin in Coordinately Regulating Branched Actin Networks. Journal of Biological Chemistry. 2014; 289:28856-28869.

33. Ammer AG, Weed SA. Cortactin branches out: roles in regulating protrusive actin dynamics. Cell Motil Cytoskeleton. 2008; 65:687-707.

34. Kinley AW, Weed SA, Weaver AM, Karginov AV, Bissonette E, Cooper JA, Parsons JT. Cortactin interacts with WIP in regulating Arp2/3 activation and membrane protrusion. Current biology. 2003; 13:384-393.

35. Noy E, Fried S, Matalon O, Barda-Saad M. WIP remodeling actin behind the scenes: how WIP reshapes immune and other functions. Int J Mol Sci. 2012; 13:7629-7647.

36. Garcia E, Ragazzini C, Yu X, Cuesta-Garcia E, Bernardino de la Serna J, Zech T, Sarrio D, Machesky LM, Anton IM. WIP and WICH/WIRE co-ordinately control invadopodium formation and maturation in human breast cancer cell invasion. Sci Rep. 2016; 6:23590.
37. Yamada H, Takeda T, Michiue H, Abe T, Takei K. Actin bundling by dynamin 2 and cortactin is implicated in cell migration by stabilizing filopodia in human non-small cell lung carcinoma cells. Int J Oncol. 2016; 49:877-886.

38. Ma W, Wang Y, Yao X, Xu Z, An L, Yin M. The role of Exo70 in vascular smooth muscle cell migration. Cellular \& molecular biology letters. 2016; 21:20.

39. Luo L. Actin cytoskeleton regulation in neuronal morphogenesis and structural plasticity. Annual review of cell and developmental biology. 2002; 18:601-635.

40. Johnston SA, Bramble JP, Yeung CL, Mendes PM, Machesky LM. Arp2/3 complex activity in filopodia of spreading cells. BMC Cell Biol. 2008; 9:65.

41. Goley ED, Welch MD. The ARP2/3 complex: an actin nucleator comes of age. Nature reviews Molecular cell biology. 2006; 7:713-726.

42. Garcia-Ponce A, Citalan-Madrid AF, Velazquez-Avila M, Vargas-Robles H, Schnoor M. The role of actin-binding proteins in the control of endothelial barrier integrity. Thromb Haemost. 2015; 113:20-36.

43. Weaver AM, Karginov AV, Kinley AW, Weed SA, Li Y, Parsons JT, Cooper JA. Cortactin promotes and stabilizes Arp2/3-induced actin filament network formation. Current Biology. 2001; 11:370-374.

44. Boczkowska M, Rebowski G, Kast DJ, Dominguez R. Structural analysis of the transitional state of Arp2/3 complex activation by two actin-bound WCAs. Nature Communications. 2014; 5.

45. Oser M, Yamaguchi H, Mader CC, Bravo-Cordero JJ, Arias M, Chen X, Desmarais V, van Rheenen J, Koleske AJ, Condeelis J. Cortactin regulates cofilin and N-WASp activities to control the stages of invadopodium assembly and maturation. J Cell Biol. 2009; 186:571-587.

46. Cosen-Binker LI, Kapus A. Cortactin: The Gray Eminence of the Cytoskeleton. Physiology. 2006; 21:352-361.

47. Illes A, Enyedi B, Tamas P, Balazs A, Bogel G, Buday L. Inducible phosphorylation of cortactin is not necessary for cortactin-mediated actin polymerisation. Cellular signalling. 2006; 18:830-840.

48. Siton O, Ideses Y, Albeck S, Unger T, Bershadsky AD, Gov NS, Bernheim-Groswasser A. Cortactin releases the brakes in actin- based motility by enhancing WASPVCA detachment from Arp2/3 branches. Curr Biol. 2011; 21:2092-2097.

49. Ditlev JA, Michalski PJ, Huber G, Rivera GM, Mohler WA, Loew LM, Mayer BJ. Stoichiometry of Nck-dependent actin polymerization in living cells. The Journal of cell biology. 2012; 197:643-658.

50. Peterson JR, Bickford LC, Morgan D, Kim AS, Ouerfelli O, Kirschner MW, Rosen MK. Chemical inhibition of N-WASP by stabilization of a native autoinhibited conformation. Nature structural \& molecular biology. 2004; 11:747-755.

51. Rohatgi R, Nollau P, Ho HYH, Kirschner MW, Mayer BJ. Nck and Phosphatidylinositol 4,5-Bisphosphate 
Synergistically Activate Actin Polymerization through the N-WASP-Arp2/3 Pathway. Journal of Biological Chemistry. 2001; 276:26448-26452.

52. Carlier MF, Nioche P, Broutin-L'Hermite I, Boujemaa R, Le Clainche C, Egile C, Garbay C, Ducruix A, Sansonetti P, Pantaloni D. GRB2 Links Signaling to Actin Assembly by Enhancing Interaction of Neural Wiskott-Aldrich Syndrome Protein (N-WASp) with Actin-related Protein (ARP2/3) Complex. Journal of Biological Chemistry. 2000; 275:21946-21952.

53. Clark ES, Weaver AM. A new role for cortactin in invadopodia: regulation of protease secretion. European journal of cell biology. 2008; 87:581-590.

54. Alblazi KMO, Siar CH. Cellular Protrusions -- Lamellipodia, Filopodia, Invadopodia and Podosomes - and their Roles in Progression of Orofacial Tumours: Current Understanding. Asian Pacific Journal of Cancer Prevention. 2015; 16: 2187-2191.

55. Linder $\mathrm{S}$. The matrix corroded: podosomes and invadopodia in extracellular matrix degradation. Trends in Cell Biology. 2007; 17:107-117.

56. Weaver AM. Invadopodia: specialized cell structures for cancer invasion. Clin Exp Metastasis. 2006; 23:97-105.

57. Kirkbride KC, Sung BH, Sinha S, Weaver AM. Cortactin: a multifunctional regulator of cellular invasiveness. Cell adhesion \& migration. 2011; 5:187-198.

58. Bryce NS, Clark ES, Leysath JL, Currie JD, Webb DJ, Weaver AM. Cortactin promotes cell motility by enhancing lamellipodial persistence. Curr Biol. 2005; 15:1276-1285.

59. Tehrani S, Faccio R, Chandrasekar I, Ross FP, Cooper JA. Cortactin has an essential and specific role in osteoclast actin assembly. Mol Biol Cell. 2006; 17:2882-2895.

60. Van Rossum AG, Moolenaar WH, Schuuring E. Cortactin affects cell migration by regulating intercellular adhesion and cell spreading. Exp Cell Res. 2006; 312:1658-1670.

61. Kempiak SJ, Yamaguchi H, Sarmiento C, Sidani M, Ghosh M, Eddy RJ, Desmarais V, Way M, Condeelis J, Segall JE. A neural Wiskott-Aldrich Syndrome protein-mediated pathway for localized activation of actin polymerization that is regulated by cortactin. J Biol Chem. 2005; 280: 5836-5842.

62. Unsworth KE, Way M, McNiven M, Machesky L, Holden DW. Analysis of the mechanisms of Salmonellainduced actin assembly during invasion of host cells and intracellular replication. Cell Microbiol. 2004; 6:1041-1055.

63. Khaitlina SY. Intracellular transport based on actin polymerization. Biochemistry (Mosc). 2014; 79:917-927.

64. Ren G, Crampton MS, Yap AS. Cortactin: Coordinating adhesion and the actin cytoskeleton at cellular protrusions. Cell Motil Cytoskeleton. 2009; 66:865-873.

65. He Y, Ren Y, Wu B, Decourt B, Lee AC, Taylor A, Suter DM. Src and cortactin promote lamellipodia protrusion and filopodia formation and stability in growth cones. Mol Biol Cell. 2015; 26:3229-3244.
66. Webb BA, Eves R, Mak AS. Cortactin regulates podosome formation: roles of the protein interaction domains. Experimental cell research. 2006; 312:760-769.

67. Van Audenhove I, Debeuf N, Boucherie C, Gettemans J. Fascin actin bundling controls podosome turnover and disassembly while cortactin is involved in podosome assembly by its SH3 domain in THP-1 macrophages and dendritic cells. Biochim Biophys Acta. 2015; 1853: 940-952.

68. Menon M, Askinazi OL, Schafer DA. Dynamin2 organizes lamellipodial actin networks to orchestrate lamellar actomyosin. PLoS One. 2014; 9:e94330.

69. Mooren OL, Kotova TI, Moore AJ, Schafer DA. Dynamin2 GTPase and cortactin remodel actin filaments. J Biol Chem. 2009; 284:23995-24005.

70. Marioni G, Zanoletti E, Mazzoni A, Gianatti A, Valentini E, Girasoli L, Guariento M, Giacomelli L, Martini A, Blandamura S. Cortactin and phosphorylated cortactin tyr466 expression in temporal bone carcinoma. American journal of otolaryngology. 2017; 38:208-212.

71. Iki J, Inoue A, Bito H, Okabe S. Bi-directional regulation of postsynaptic cortactin distribution by BDNF, NMDA receptor activity. The European journal of neuroscience. 2005; 22:2985-2994.

72. Martin KH, Jeffery ED, Grigera PR, Shabanowitz J, Hunt DF, Parsons JT. Cortactin phosphorylation sites mapped by mass spectrometry. J Cell Sci. 2006; 119:2851-2853.

73. Head JA, Jiang D, Li M, Zorn LJ, Schaefer EM, Parsons JT, Weed SA. Cortactin tyrosine phosphorylation requires Rac1 activity and association with the cortical actin cytoskeleton. Mol Biol Cell. 2003; 14:3216-3229.

74. Hammer A, Laghate S, Diakonova M. Src tyrosyl phosphorylates cortactin in response to prolactin. Biochem Biophys Res Commun. 2015; 463:644-649.

75. Evans JV, Ammer AG, Jett JE, Bolcato CA, Breaux JC, Martin KH, Culp MV, Gannett PM, Weed SA. Src binds cortactin through an SH2 domain cystine-mediated linkage. J Cell Sci. 2012; 125:6185-6197.

76. Rosenberg BJ, Gil-Henn H, Mader CC, Halo T, Yin T, Condeelis J, Machida K, Wu YI, Koleske AJ. Phosphorylated cortactin recruits Vav2 guanine nucleotide exchange factor to activate Rac3 and promote invadopodial function in invasive breast cancer cells. Molecular biology of the cell. 2017; 28:1347-1360.

77. Ethell IM, Pasquale EB. Molecular mechanisms of dendritic spine development and remodeling. Progress in neurobiology. 2005; 75:161-205.

78. Boyle SN, Michaud GA, Schweitzer B, Predki PF, KoleskeAJ. A critical role for cortactin phosphorylation by Abl-family kinases in PDGF-induced dorsal-wave formation. Curr Biol. 2007; 17:445-451.

79. Sangrar W, Gao Y, Scott M, Truesdell P, Greer PA. Fermediated cortactin phosphorylation is associated with efficient fibroblast migration and is dependent on reactive 
oxygen species generation during integrin-mediated cell adhesion. Mol Cell Biol. 2007; 27:6140-6152.

80. Zhang X, Shrikhande U, Alicie BM, Zhou Q, Geahlen RL. Role of the protein tyrosine kinase Syk in regulating cellcell adhesion and motility in breast cancer cells. Mol Cancer Res. 2009; 7:634-644.

81. Garcia-Castillo J, Pedersen K, Angelini PD, Bech-Serra JJ, Colome N, Cunningham MP, Parra-Palau JL, Canals F, Baselga J, Arribas J. HER2 carboxyl-terminal fragments regulate cell migration and cortactin phosphorylation. J Biol Chem. 2009; 284:25302-25313.

82. Lai FP, Szczodrak M, Oelkers JM, Ladwein M, Acconcia F, Benesch S, Auinger S, Faix J, Small JV, Polo S, Stradal TE, Rottner K. Cortactin promotes migration and plateletderived growth factor-induced actin reorganization by signaling to Rho-GTPases. Mol Biol Cell. 2009; 20: 3209-3223.

83. Kruchten AE, Krueger EW, Wang Y, McNiven MA. Distinct phospho-forms of cortactin differentially regulate actin polymerization and focal adhesions. Am J Physiol Cell Physiol. 2008; 295:C1113-1122.

84. Huang J, Asawa T, Takato T, Sakai R. Cooperative roles of Fyn and cortactin in cell migration of metastatic murine melanoma. J Biol Chem. 2003; 278:48367-48376.

85. Webb BA, Zhou S, Eves R, Shen L, Jia L, Mak AS. Phosphorylation of cortactin by p21-activated kinase. Arch Biochem Biophys. 2006; 456:183-193.

86. Eiseler T, Hausser A, De Kimpe L, Van Lint J, Pfizenmaier K. Protein kinase D controls actin polymerization and cell motility through phosphorylation of cortactin. J Biol Chem. 2010; 285:18672-18683.

87. De Kimpe L, Janssens K, Derua R, Armacki M, Goicoechea S, Otey C, Waelkens E, Vandoninck S, Vandenheede JR, Seufferlein T, Van Lint J. Characterization of cortactin as an in vivo protein kinase $\mathrm{D}$ substrate: interdependence of sites and potentiation by Src. Cell Signal. 2009; 21:253-263.

88. Yin HL, Janmey PA. Phosphoinositide regulation of the actin cytoskeleton. Annual review of physiology. 2003; 65:761-789.

89. Grassart A, Meas-Yedid V, Dufour A, Olivo-Marin JC, Dautry-Varsat A, Sauvonnet N. Pak1 phosphorylation enhances cortactin-N-WASP interaction in clathrin-caveolinindependent endocytosis. Traffic. 2010; 11:1079-1091.

90. Higgs H, Pollard T. Regulation of actin filament network formation through ARP2/3 complex: activation by a diverse array of proteins. Annu Rev Biochem. 2001; 70:649-676.

91. Zhang Y, Zhang M, Dong H, Yong S, Li X, Olashaw N, Kruk PA, Cheng JQ, Bai W, Chen J, Nicosia SV, Zhang X. Deacetylation of cortactin by SIRT1 promotes cell migration. Oncogene. 2009; 28:445-460.

92. Motonishi S, Nangaku M, Wada T, Ishimoto Y, Ohse T, Matsusaka T, Kubota N, Shimizu A, Kadowaki T, Tobe K, Inagi R. Sirtuin1 Maintains Actin Cytoskeleton by
Deacetylation of Cortactin in Injured Podocytes. J Am Soc Nephrol. 2015; 26:1939-1959.

93. Catarino T, Ribeiro L, Santos SD, Carvalho AL. Regulation of synapse composition by protein acetylation: the role of acetylated cortactin. J Cell Sci. 2013; 126:149-162.

94. Castro-Castro A, Janke C, Montagnac G, Paul-Gilloteaux P, Chavrier P. ATAT1/MEC-17 acetyltransferase and HDAC6 deacetylase control a balance of acetylation of alpha-tubulin and cortactin and regulate MT1-MMP trafficking and breast tumor cell invasion. European journal of cell biology. 2012; 91:950-960.

95. Zhang X, Yuan Z, Zhang Y, Yong S, Salas-Burgos A, Koomen J, Olashaw N, Parsons JT, Yang XJ, Dent SR, Yao TP, Lane WS, Seto E. HDAC6 modulates cell motility by altering the acetylation level of cortactin. Mol Cell. 2007; 27:197-213.

96. Ran J, Yang Y, Li D, Liu M, Zhou J. Deacetylation of alphatubulin and cortactin is required for HDAC6 to trigger ciliary disassembly. Sci Rep. 2015; 5:12917.

97. Sun X, Li C, Zhuang C, Gilmore WC, Cobos E, Tao Y, Dai Z. Abl interactor 1 regulates Src-Id1-matrix metalloproteinase 9 axis and is required for invadopodia formation, extracellular matrix degradation and tumor growth of human breast cancer cells. Carcinogenesis. 2009; 30:2109-2116.

98. Rey M, Irondelle M, Waharte F, Lizarraga F, Chavrier P. HDAC6 is required for invadopodia activity and invasion by breast tumor cells. Eur J Cell Biol. 2011; 90:128-135.

99. Hou H, Zhao L, Chen W, Li J, Zuo Q, Zhang G, Zhang X, Li X. Expression and significance of cortactin and HDAC6 in human prostatic foamy gland carcinoma. Int J Exp Pathol. 2015; 96:248-254.

100. Haakenson J, Zhang X. HDAC6 and ovarian cancer. Int J Mol Sci. 2013; 14:9514-9535.

101. Friedl P, Wolf K. Tumour-cell invasion and migration: diversity and escape mechanisms. Nat Rev Cancer. 2003; 3:362-374.

102. Sung BH, Zhu X, Kaverina I, Weaver AM. Cortactin controls cell motility and lamellipodial dynamics by regulating ECM secretion. Curr Biol. 2011; 21:1460-1469.

103. Sibony-Benyamini H, Gil-Henn H. Invadopodia: the leading force. Eur J Cell Biol. 2012; 91:896-901.

104. Steffen A, Le Dez G, Poincloux R, Recchi C, Nassoy P, Rottner K, Galli T, Chavrier P. MT1-MMP-dependent invasion is regulated by TI-VAMP/VAMP7. Curr Biol. 2008; 18:926-931.

105. Artym VV, Zhang Y, Seillier-Moiseiwitsch F, Yamada KM, Mueller SC. Dynamic interactions of cortactin and membrane type 1 matrix metalloproteinase at invadopodia: defining the stages of invadopodia formation and function. Cancer Res. 2006; 66:3034-3043.

106. Bowden ET, Onikoyi E, Slack R, Myoui A, Yoneda T, Yamada KM, Mueller SC. Co-localization of cortactin and 
phosphotyrosine identifies active invadopodia in human breast cancer cells. Exp Cell Res. 2006; 312:1240-1253.

107. Clark ES, Whigham AS, Yarbrough WG, Weaver AM. Cortactin is an essential regulator of matrix metalloproteinase secretion and extracellular matrix degradation in invadopodia. Cancer Res. 2007; 67:4227-4235.

108. You TK, Kim KM, Noh SJ, Bae JS, Jang KY, Chung MJ, Moon WS, Kang MJ, Lee DG, Park HS. Expressions of E-cadherin, Cortactin and MMP-9 in Pseudoepitheliomatous Hyperplasia and Squamous Cell Carcinoma of the Head and Neck: Their Relationships with Clinicopathologic Factors and Prognostic Implication. Korean J Pathol. 2012; 46:331-340.

109. Zhao G, Zhang H, Huang Z, Lv L, Yan F. Cortactin and Exo70 mediated invasion of hepatoma carcinoma cells by MMP-9 secretion. Molecular biology reports. 2016; 43:407-414.

110. Luo ML, Shen XM, Zhang Y, Wei F, Xu X, Cai Y, Zhang X, Sun YT, Zhan QM, Wu M, Wang MR. Amplification and overexpression of CTTN (EMS1) contribute to the metastasis of esophageal squamous cell carcinoma by promoting cell migration and anoikis resistance. Cancer Res. 2006; 66:11690-11699.

111. Myllykangas S, Bohling T, Knuutila S. Specificity, selection and significance of gene amplifications in cancer. Semin Cancer Biol. 2007; 17:42-55.

112. Yuan BZ, Zhou X, Zimonjic DB, Durkin ME, Popescu NC. Amplification and Overexpression of the EMS 1 Oncogene, a Possible Prognostic Marker, in Human Hepatocellular Carcinoma. The Journal of Molecular Diagnostics. 2003; 5:48-53.

113. Agarwal E, Robb CM, Smith LM, Brattain MG, Wang J, Black JD, Chowdhury S. Role of Akt2 in regulation of metastasis suppressor 1 expression and colorectal cancer metastasis. Oncogene. 2017; 36:3104-3118.

114. Lazar V, Ecsedi S, Szollosi AG, Toth R, Vizkeleti L, Rakosy Z, Begany A, Adany R, Balazs M. Characterization of candidate gene copy number alterations in the 11q13 region along with BRAF, NRAS mutations in human melanoma. Mod Pathol. 2009; 22:1367-1378.

115. Luo ML, Wang MR. CTTN (EMS1): an oncogene contributing to the metastasis of esophageal squamous cell carcinoma. Cell Res. 2007; 17:298-300.
116. Kelley LC, Weed SA. Cortactin is a substrate of activated Cdc42-associated kinase 1 (ACK1) during ligand-induced epidermal growth factor receptor downregulation. PLoS One. 2012; 7:e44363.

117. Desmarais V, Yamaguchi H, Oser M, Soon L, Mouneimne G, Sarmiento C, Eddy R, Condeelis J. N-WASP and cortactin are involved in invadopodium-dependent chemotaxis to EGF in breast tumor cells. Cell Motil Cytoskeleton. 2009; 66:303-316.

118. Huo W, Xiao Q, Xi C, Yong G, Lei H, Hao X, Feng Y, Ren Z. Asporin enhances colorectal cancer metastasis through activating the EGFR/Src/cortactin signaling pathway. Oncotarget. 2016; 7:73402-73413. http://doi.org/10.18632/ oncotarget.12336.

119. Zhi N, Dan L, Bin Y, Wen Y, Hui Z, Yi X, Yuan J, Xiao Z, Chong M. High expression of PTBP1 promote invasion of colorectal cancer by alternative splicing of cortactin. Oncotarget. 2017; 8:36185-36202. http://doi.org/10.18632/ oncotarget. 15873 .

120. Zhang L, Liu T, Huang Y, Liu J. microRNA-182 inhibits the proliferation and invasion of human lung adenocarcinoma cells through its effect on human cortical actin-associated protein. International journal of molecular medicine. 2011; 28:381-388.

121. Garcia Ponce A, Citalan Madrid AF, Vargas Robles H, Chanez Paredes S, Nava P, Betanzos A, Zarbock A, Rottner K, Vestweber D, Schnoor M. Loss of cortactin causes endothelial barrier dysfunction via disturbed adrenomedullin secretion and actomyosin contractility. Sci Rep. 2016; 6:29003.

122. Lam PY, Mangos S, Green JM, Reiser J, Huttenlocher A. In vivo imaging and characterization of actin microridges. PLoS One. 2015; 10:e0115639.

123. Mader CC, Oser M, Magalhaes MA, Bravo-Cordero JJ, Condeelis J, Koleske AJ, Gil-Henn H. An EGFR-SrcArg-cortactin pathway mediates functional maturation of invadopodia and breast cancer cell invasion. Cancer Res. 2011; 71:1730-1741. 